\title{
Utilization Study of Antihypertensive Medicines Among Insured Patients at a Public Tertiary Healthcare Facility in Nigeria
}

\author{
Roland N. Okoro ${ }^{1, *}$, Chijioke Nmeka ${ }^{2}$, Patrick O. Erah ${ }^{3}$ \\ ${ }^{1}$ Department of Clinical Pharmacy and Pharmacy Administration, Faculty of Pharmacy, University of Maiduguri, \\ P.M.B. 1069, Maiduguri, Borno State, Nigeria \\ ${ }^{2}$ Department of Pharmacy, University of Nigeria Teaching Hospital, Ituku-Ozalla, Enugu, Nigeria \\ ${ }^{3}$ Department of Clinical Pharmacy and Pharmacy Practice, Faculty of Pharmacy, University of Benin, Benin City, \\ Nigeria
}

Authors' Contributions

1 Conception \& Study Design, Data Collection,

Data Analysis, Drafting.

2 Data Collection, Critical Review.

3 Conception \& Study Design, Data Analysis,

Critical Review.

\section{Article info.}

Received: September 12, 2019

Accepted: December 12, 2019

Funding Source: Nil

Conflict of Interest: Nil

Cite this article: Okoro RN, Nmeka C, Erah

PO. Utilization Study of Antihypertensive

Medicines Among Insured Patients at a Public

Tertiary Healthcare Facility in Nigeria. RADS J

Pharm Pharm Sci. 2019; 7(4): 174-180.

*Address of Correspondence Author: orolandn@gmail.com

\section{ABSTRACT}

Background: Access to essential medicines through health insurance contributes substantially towards achieving hypertension control in hypertensive sub-population of a nation.

Objectives: This study aimed to estimate the gender-based antihypertensive medicines use, to describe utilization patterns, and to estimate prescribing adherence to the health insurance guideline.

Methods: A descriptive, cross-sectional, retrospective review of paper-based prescriptions with at least an antihypertensive medicine written for insured outpatients from $1^{\text {st }}$ January $-31^{\text {st }}$ December 2013 at a Nigerian Federal Teaching Hospital was conducted. The prescription volume and Anatomic Therapeutic Chemical/Defined Daily Dose (DDD) methodology was used to estimate the extent of utilization of antihypertensive medicines among the study population. Drug utilization ninety percent (DU90\%) was used to quantify the index of adherence to the National Health Insurance Scheme (NHIS) guideline. Differences in proportions were investigated with Pearson chi-square test $\left(x^{2}\right)$. A p-value of less than 0.05 was considered statistically significant.

Results: Females recorded significantly higher antihypertensive medicines use compared to their male counterparts $(61.5 \%$ versus $38.5 \%, p<0.05)$. Diuretics (32.1\% and 9935.28 DDD) and calcium channel blockers $(32.1 \%$ and 8286 DDD) were the most commonly prescribed and utilized antihypertensive medicine classes. The index of adherence to the NHIS standard treatment guideline is $80.7 \%$.

Conclusion: This study showed that diuretics (most frequently hydrochlorothiazide) and calcium channel blockers (most frequently amlodipine) were the most utilized antihypertensive medicine classes. Physicians' prescribing patterns fell below the hundred percent benchmark of the country's National Health Insurance programme guideline with respect to antihypertensive medicines.

Keywords: Antihypertensive medicines, defined daily dose, health insurance, hypertension, Nigeria. 


\section{INTRODUCTION}

Hypertension is a chronic disease with a significant risk for cardiovascular adverse outcomes [1]. There is an increasing incidence of hypertension in Africa due to the adoption of western lifestyles. To substantiate this, the World Health Organization has reported that 9.2 deaths in 2000 were due to cardiovascular diseases [2]. A much higher value has been projected in 2025 [3]. Against this background, increased utilization of cardiovascular medicines especially antihypertensive medicines is expected in Africa, including Nigeria.

Despite this projected rise in the incidence of hypertension and the number of antihypertensive prescriptions, the majority of the population will not be able to purchase these medicines due to their low purchasing power. This underscores the need for an efficient and effective health insurance programme in African countries. An earlier study has demonstrated that health insurance with medicine coverage is positively correlated with higher utilization of medicines at an affordable cost [4]. Due to expected increase accessibility to essential medicines by the majority of the population, health insurance has the capacity to reduce the cardiovascular adverse outcome associated with hypertension in Africa, especially Nigeria. On the other hand, increased access to medicine through health insurance may engender irrational use of medicines. This justifies the need to evaluate medicine prescribing pattern in this programme with a view to developing appropriate interventions that will ensure rational utilization of medicines.

A literature search showed that many studies have evaluated antihypertensive medicine utilization patterns in different parts of Nigeria [5-14]. Though, these studies were conducted in non-health insurance settings. To our knowledge, no published study exists on the utilization of antihypertensive medicines in health insurance in Nigeria, hence the need for the present study. This study is aimed to estimate the gender-based antihypertensive medicines use, to describe utilization patterns, and to estimate prescribing adherence to health insurance guideline.

\section{MATERIALS AND METHODS}

\section{Study Design and Setting}

This was a descriptive, cross-sectional, retrospective study of paper-based prescriptions that was written for insured outpatients during the twelve months period of 2013. The study was conducted at the University of Nigeria Teaching Hospital (UNTH), Enugu. UNTH has about 500-bed capacity and is one of the 20 federal, teaching hospitals in Nigeria [15], and also a participating hospital in the National Health Insurance Scheme (NHIS).

\section{Sample Size Calculation}

The sample size was derived using the Yamane equation for proportions, as follows [16]:

$N=\frac{N}{1+N(e)^{2}}$

Where:

$\mathrm{N}=$ Size of the population, which was 9146

$\mathrm{e}=$ Level of precision, usually set at 0.05

$\mathrm{n}=\frac{9146}{1+9146(0.05)^{2}}=400$

This formula gave a sample size of at least 400 , to boost the power of the study, a sampling interval of 20 was chosen to randomly select prescription sheets for this study. Simple balloting was used to select the first prescription sheet.

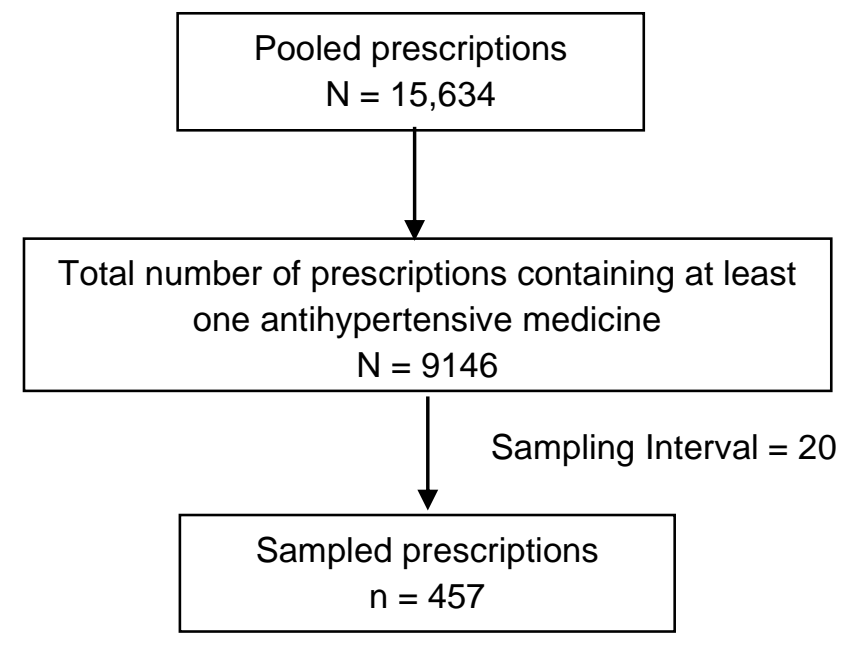

The Sampling Flow Chart 


\section{Ethical Approval}

Ethical approval was obtained from the Research and Ethics Committee of the University of Nigeria Teaching Hospital (UNTH), Enugu.

\section{Data Collection}

Data were collected from August - September 2014 without any identifiable patient's information. Information collected from patients included age, sex, antihypertensive medicines prescribed (name, class, route of administration, dosage form, strength, dose, frequency of administration, and duration of treatment). Defined daily doses (DDDs) of antihypertensive medicines were extracted from the WHO Collaborating Centre for Drug Statistics list of DDD [17].

\section{Data Analysis}

Anatomic Therapeutic Chemical (ATC)/Defined Daily Dose (DDD) [17] was employed to categorize antihypertensive medicines. Number/volume of DDD and drug utilization ninety percent (DU90\%) [18] were used to express antihypertensive medicine utilization. Index of adherence to standard treatment guideline [19] was used to determine the prescribing quality according to Bergman et al. (1998) [18].

\section{Percentage Index of Adherence to Guideline =}

Number of DDDs in Guideline $\mathrm{x} 100$

Total Number of DDDs in DU90\% Segment

\section{Statistical Analyses}

Descriptive statistics (frequencies, percentages, mean or mean \pm standard deviation, and median) and inferential statistics (Pearson chi-square test) were used for statistical analyses. A p-value less than 0.05 was considered statistically significant. All statistical analyses were carried out using Statistical Package for Social Sciences (SPSS) version 20 for Windows ${ }^{\circledR}$.

\section{RESULTS}

A total of 457 prescriptions were randomly selected for this study. Each prescription contained an average of $2.3 \pm 0.8$ antihypertensive medicines. Males received a slightly higher average number of prescriptions (2.4 versus 2.2) compared with females. Analysis of the demographics of the prescriptions showed that most females and males were between 50 - 64 years of age. The detailed patients' age distribution is shown in Table 1.

The antihypertensive medication use was significantly $(p<0.05)$ higher among females $284(61.5 \%)$ than males $173(38.5 \%)$.

Table 1. Age distribution of the study population according to sex $(\mathrm{N}=457)$.

\begin{tabular}{|c|c|c|}
\hline $\begin{array}{c}\text { Age Group } \\
\text { (years) }\end{array}$ & \multicolumn{2}{|c|}{ Sex (n (\%)) } \\
\hline & Female & Male \\
\hline $20-34$ & $4(1.4)$ & $2(1.2)$ \\
\hline $35-49$ & $81(28.5)$ & $18(10.4)$ \\
\hline $50-64$ & $86(30.3)$ & $77(44.5)$ \\
\hline$\geq 65$ & $4(1.4)$ & $18(10.4)$ \\
\hline Not indicated & $109(38.4)$ & $58(33.5)$ \\
\hline Total & $284(100.0)$ & $173(100.0)$ \\
\hline
\end{tabular}

Table 2. Relative use of antihypertensive mono therapy and combination therapies $(N=457)$.

\begin{tabular}{|c|c|c|c|c|c|c|c|}
\hline $\begin{array}{c}\text { Mono } \\
\text { Therapy }\end{array}$ & $\begin{array}{c}\mathbf{N}=\mathbf{7 0} \\
\mathbf{n}(\%)\end{array}$ & Dual Therapy & $\begin{array}{c}\mathbf{N}=\mathbf{2 4 7} \\
\mathbf{n}(\%)\end{array}$ & Triple Therapy & $\begin{array}{c}\mathbf{N}=\mathbf{1 2 9} \\
\mathbf{n}(\%)\end{array}$ & Quadruple Therapy & $\begin{array}{c}\mathbf{N}=\mathbf{1 1} \\
\mathbf{n}(\%)\end{array}$ \\
\hline DUR & $21(30.0)$ & DUR,CCB & $101(40.9)$ & DUR,CCB,ARB & $70(54.2)$ & DUR,CCB,ACEI,CAA & $3(27.2)$ \\
\hline CCB & $18(25.7)$ & DUR,ACEI & $85(34.4)$ & DUR,CCB,ACEI & $51(39.4)$ & DUR,CCB,ACEI,BB & $2(18.2)$ \\
\hline ARB & $13(18.6)$ & DUR,ARB & $43(17.4)$ & DUR,ACEI,BB & $2(1.6)$ & DUR,CCB,ACEI,ARB & $1(9.1)$ \\
\hline ACEI & $11(15.7)$ & CCB,ACEI & $11(4.5)$ & DUR,CCB,BB & $2(1.6)$ & DUR,CCB,ARB,BB & $1(9.1)$ \\
\hline CAA & $4(5.7)$ & CCB,ARB & $3(1.2)$ & DUR,ACEI,ARB & $1(0.8)$ & DUR,CCB,ARB,CAA & $1(9.1)$ \\
\hline BB & $3(4.3)$ & DUR,CAA & $2(0.8)$ & CCB,ARB,CAA & $1(0.8)$ & DUR,ARB,CAA,BB & $1(9.1)$ \\
\hline & & CCB,CAA & $1(0.4)$ & DUR,ARB,BB & $1(0.8)$ & DUR,CCB,CAA,BB & $1(9.1)$ \\
\hline & & CAA,ARB & $1(0.4)$ & DUR,ARB,CAA & $1(0.8)$ & CCB,CA,BB,PVD & $1(9.1)$ \\
\hline
\end{tabular}

DUR: Diuretic, CCB: Calcium Channel Blocker, ACEl: Angiotensin Converting Enzyme Inhibitor, ARB: Angiotensin Receptor Blocker, BB: Beta-Blocker, CAA: Centrally Acting Agent, PVD: Peripheral Vasodilator 
Table 3. Overall frequency of antihypertensive medicines use $(\mathrm{N}=945)$.

\begin{tabular}{|c|c|c|}
\hline $\begin{array}{l}\text { Medicine } \\
\text { Class }\end{array}$ & Medicine Name & n (\%) \\
\hline \multirow{3}{*}{$\begin{array}{l}\text { Diuretics } \\
N=304 \\
(32.2 \%)\end{array}$} & Hctz & $\begin{array}{c}265 \\
(28.1) \\
\end{array}$ \\
\hline & Spironolactone & $19(2.0)$ \\
\hline & Furosemide & $20(2.1)$ \\
\hline \multirow{3}{*}{$\begin{array}{c}\text { CCBs } \\
N=304 \\
(32.2 \%)\end{array}$} & Amlodipine & $\begin{array}{c}239 \\
(25.3)\end{array}$ \\
\hline & Nifedipine & $53(5.6)$ \\
\hline & Felodipine & $12(1.3)$ \\
\hline \multirow{3}{*}{$\begin{array}{c}\text { ACEls } \\
N=163 \\
(17.2 \%)\end{array}$} & Lisinopril & $\begin{array}{c}160 \\
(16.9)\end{array}$ \\
\hline & Enalapril & $2(0.2)$ \\
\hline & Thiapril & $1(0.1)$ \\
\hline \multirow{6}{*}{$\begin{array}{c}\text { ARBs } \\
\mathrm{N}=86(9.1 \%)\end{array}$} & Losartan & $32(3.4)$ \\
\hline & Valsartan & $29(3.1)$ \\
\hline & Telmisartan & $10(1.1)$ \\
\hline & Irbesartan & $7(0.7)$ \\
\hline & Candesartan & $7(0.7)$ \\
\hline & Olmesartan & $1(0.1)$ \\
\hline \multirow{4}{*}{$\begin{array}{c}\text { BBs } \\
\mathrm{N}=12(1.2 \%)\end{array}$} & Propranolol & $3(0.3)$ \\
\hline & Atenolol & $3(0.3)$ \\
\hline & Metoprolol & $4(0.4)$ \\
\hline & Carvedilol & $2(0.2)$ \\
\hline $\begin{array}{c}\text { CAA } \\
\mathrm{N}=14(1.5 \%) \\
\end{array}$ & Methyl dopa & $14(1.5)$ \\
\hline $\begin{array}{c}\text { PVD } \\
\mathrm{N}=1(0.1 \%)\end{array}$ & Hydralazine & $1(0.1)$ \\
\hline \multirow{10}{*}{$\begin{array}{c}\text { FDC } \\
\mathrm{N}=61(6.5 \%)\end{array}$} & Hctz+Amiloride & $32(3.5)$ \\
\hline & $\begin{array}{c}\text { Valsartan+Amlodipine }+\mathrm{H} \\
\text { ctz }\end{array}$ & $10(1.1)$ \\
\hline & Valsartan+Hctz & $8(0.8)$ \\
\hline & Irebesartan+Hctz & $3(0.3)$ \\
\hline & Telmisartan+Hctz & $2(0.2)$ \\
\hline & Valsartan+Amlodipine & $2(0.2)$ \\
\hline & Candesartan+Hctz & $1(0.1)$ \\
\hline & Enalapril+Hctz & $1(0.1)$ \\
\hline & Atenolol+Chlorthalidone & $1(0.1)$ \\
\hline & Amlodipine+Atorvastatin & $1(0.1)$ \\
\hline
\end{tabular}

Hctz: Hydrochlorothiazide

The distribution of single and combination therapies showed that $70(15.3 \%)$ patients received mono therapeutic prescriptions, whereas $247(54.1 \%), 129$ (28.2\%), and $11(2.4 \%)$ patients received dual, triple and quadruple therapeutic prescriptions, respectively. Analysis of individual antihypertensive medicine classes revealed diuretics $(30.0 \%)$ as the most prescribed and BBs as the least prescribed among the mono therapeutic class category. However, it is of interest to note the preference of ARB (18.6\%) over ACEI (15.7\%) in the mono therapeutic category. On the other hand, combination of various antihypertensive medicine classes showed that diuretics plus CCB (40.9\%) were the highest prescribed in the two-class combination category, diuretics plus CCB plus ARB (54.2\%) in the threeclass combination category, and diuretics plus $\mathrm{CCB}$ plus ACEI plus CAA (27.2\%) in the four-class combination category, respectively (Table 2 ).

The total volume of the antihypertensive medicine class prescribed showed that diuretics (32.2\%) and CCBs $(32.2 \%)$ were the most prescribed followed by ACEls (17.2\%). The fixed-dose combination (FDC) accounted for $6.5 \%$ of the total antihypertensive medicines prescribed. The least prescribed antihypertensive medicine class was peripheral vasodilator (PVD) which constituted only $0.1 \%$ of the total prescription volume. In the same vein, analysis of individual antihypertensive medicines revealed that hydrochlorothiazide (28.1\%), amlodipine (25.3\%), and lisinopril (16.9\%) were the most prescribed, whereas thiapril, olmesartan, and hydralazine were the least prescribed. Hydrochlorothiazide plus amiloride constituted the most prescribed fixed-dose combination (3.5\%) (Table 3).

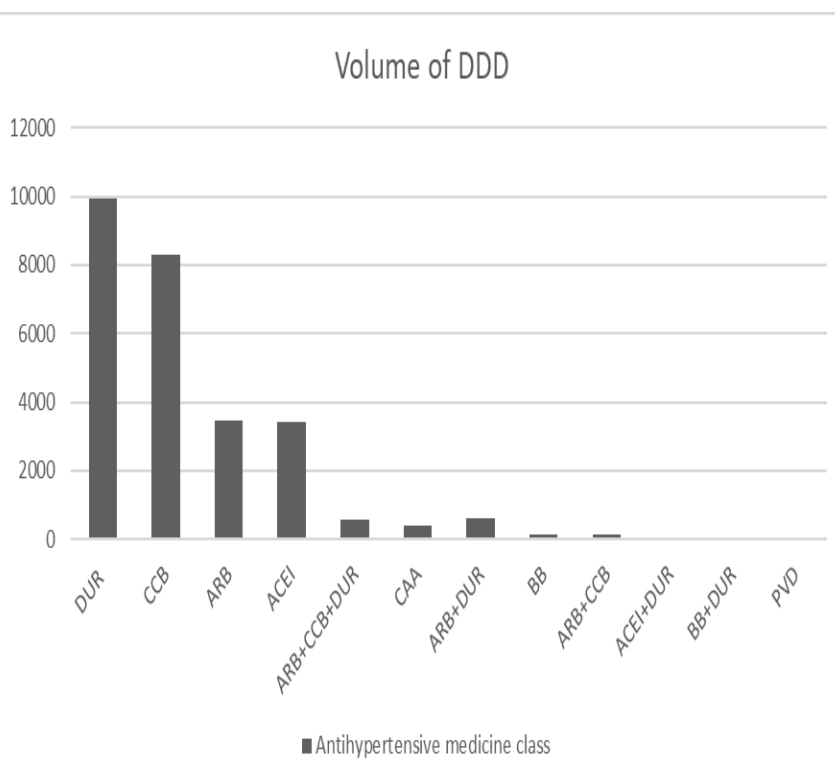

DUR: Diuretic, CCB: Calcium Channel Blocker, ACEl: Angiotensin Converting Enzyme Inhibitor, ARB: Angiotensin Receptor Blocker, BB: Beta-Blocker, CAA: Centrally Acting Agent, PVD: Peripheral Vasodilator

Figure 1. Antihypertensive medicine class utilized $(\mathrm{N}=945)$. 
Eleven antihypertensive pharmaceutical products made it to the DU90\% segment. Hydrochlorothiazide appeared first in the DU90\% segment with 7928.5 DDD thereby making it the most utilized, followed by amlodipine with 7506 DDD while ramipril appeared last with 432 DDD. The calculated index of adherence to the NHIS standard treatment guideline [19] based on DU $90 \%$ is $80.7 \%$ (Figure 2 ).

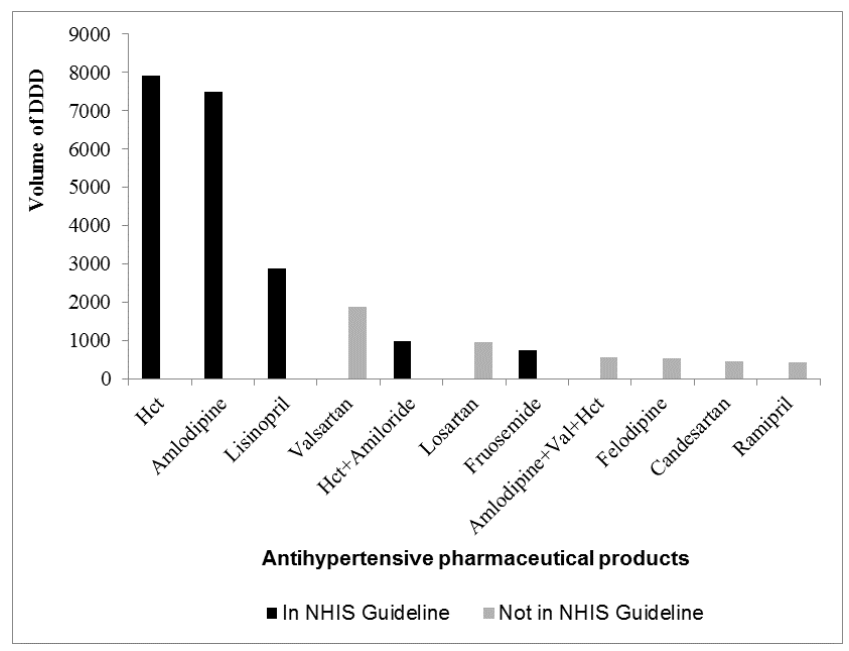

Hctz: Hydrochlorothiazide, Val: Valsartan

Figure 2. Bulk of antihypertensive medicines (DU90\%) utilized $(\mathrm{N}=11)$.

\section{DISCUSSION}

This study revealed significantly higher antihypertensive medicines use among females than males consistent with the findings of some earlier studies [5, 7-10, 13, 14, 20]. In contrast, other studies reported higher use among males [11, 21, 22]. Despite the fact that hypertension is a male predominant chronic disease, the greater proportions of females in our study may be partly explained by early healthcare seeking-behaviour of women, they have a higher probability of having medicines prescribed compared to men, who may seek emergency care at a higher rate.

However, our study showed that antihypertensive medicines use was highest among patients aged 50 64 years for both genders. This result is consistent with the findings of other similar published studies $[13,23]$. On the contrary, an earlier study reported higher use among those aged 41 - 50 years [10]. The possible explanation for the difference in age distributions observed in this study compared to our study could be geographic variations and differences in the genetic make-up of the residents which may be linked to either higher or lower hypertension occurrence rate in these age groups. Interestingly, there was a sudden drop-off in the proportion of patients that used antihypertensive medicines at 65 years or more. Financial constraints due to retirement between the ages of 60 and 70 years depending on the establishment [24] could account for this observation.

Diuretics, mainly thiazides were the most commonly utilized antihypertensive medicine class either alone or as a combination therapy in the present study. The choice of thiazide diuretics as the first-line antihypertensive agent is consistent with reports of earlier studies conducted in Nigeria [5, 7, 9, 11, 13, $14,21,25]$. The highest utilization of thiazide diuretics found by our study is also in agreement with the Nigerian NHIS guideline which recommended it as the first choice antihypertensive agent due to its ability to prevent major cardiovascular events [19]. This finding corroborates the report of heart attack prevention trial [26]. In contrast, some non-Nigerian studies reported low use of thiazide diuretics [27-29]. Despite thiazides recommendation as the first-line medicine in the management of hypertension, low use of this class indicated by these studies may not be unconnected with adverse effects concerns and poor market availability in those countries [30]. For patients that cannot take diuretics, first-step therapy with CCBs or ACEls or ARBs could be considered. Our study found CCBs as the second most frequently prescribed antihypertensive medicine class similar to the findings of some earlier studies $[8,9,11,13,21$, 25].

The present study found that a substantial number of $A R B$ or ACEl mono therapy were prescribed as the initial choice of therapy with a slight preference of ARB over ACEl as mono therapy. This observation may not be unconnected with its fewer tendencies to cause cough [31]. Overall, our study recorded ACEls prescriptions frequency similar to the result of an earlier study outside health insurance setting of the same hospital [11]. In addition, an earlier study conducted in the other part of the country reported lower utilization of ACEls [32]. Geographic differences and prescribers' characteristics could account for the variation.

The high utilization rate of poly therapy as compared to mono therapy may suggests that majority of the patients managed for hypertension during the year under review had complicated hypertension consistent with the standard treatment guideline which recommends the use of two or more antihypertensive medicines in patients with hypertension and diabetes or renal disease to achieve target blood pressure (BP) [33]. Combination therapy of antihypertensive medicines is the rational use of more than one antihypertensive agent to achieve BP goal [33-35]. Higher use of the combination of antihypertensive medicines compared to monotherapy reported by our study is consistent 
with the results of some earlier studies conducted in Nigeria [5, 7, 9, 10, 14, 22].

The limitations of this study include medicines classified as antihypertensives can have other indications (heart failure, oedema among others), pharmacy insurance claims do not contain data on new patients on antihypertensives and change/switch on therapy, clinical and laboratory findings. The study also lacked information on whether the patients actually used the dispensed medicines or not. The study findings may not reflect the current antihypertensive medicine prescribing practice of the setting studied due to the time lag between data collection and publishing of the findings. Lastly, this study was conducted in one centre, therefore the findings cannot be generalized.

\section{CONCLUSION}

Antihypertensive medicines use was significantly higher among females compared to males. Poly therapy prescriptions were significantly higher than mono therapy prescriptions. Diuretics (most frequently hydrochlorothiazide) and calcium channel blockers (most frequently amlodipine) were the most prescribed and consumed antihypertensive medicines. Prescribers' adherence to NHIS antihypertensive medicine prescribing guideline was good but less than a hundred percent benchmark of the health insurance scheme.

\section{REFERENCES}

1. The World Health Report. The Double Burden: Emerging Epidemics and Persistent Problems. Geneva: WHO. 1999. Available from: www.who.int/whr/1999/en/whr99_ch2_en.pdf. [Last updated on 1999 May, Last accessed on $30^{\text {th }}$ July, 2018].

2. World Health Report. Reducing Risks, Promoting Health Life. Geneva, Switzerland: World Health Organization. $2002 . \quad$ Available from: http://www.who.int/whr/2002/en/ [Last updated on 2002 Oct, Last accessed on $30^{\text {th }}$ July, 2018].

3. Opie LH, Seedat YK. Hypertension in Sub-Saharan Africa Populations. Circulation. 2005; 112:3562-8.

4. Blustein J. Drug Coverage and Drug Purchases by Medicare Beneficiaries with Hypertension. Health Affairs. 2000; 19:219-30.

5. Bakare OQ, Akinyinka MR, Goodman O, Kuyinu YA, Wright OK, Adeniran A, et al. Antihypertensive Use, Prescription Patterns, and Cost of Medications in a Teaching Hospital in Lagos, Nigeria. Niger J Clin Pract. 2016; 19:668-72.
6. Oke O, Adedapo OA. Antihypertensive Drug Utilization and Blood Pressure Control in a Nigerian Hypertensive Population. General Med. 2015; 3:1000169.

7. Osibogun A, Okwor TJ. Anti-Hypertensive Prescription and Cost Patterns in an Outpatient Department of a Teaching Hospital in Lagos State Nigeria. Open $\mathrm{J}$ Preventive Med. 2014; 4:156-63.

8. Eshiet UI, Yusuff KB. Anti-hypertensive Medicines Prescribing for Medical Outpatients in a Premier Teaching Hospital in Nigeria: A Probable Shift of Paradigm. Pharmacy Practice. 2014; 12:419.

9. Busari OA, Oluyonbo R, Gabriel OE, Ayodele LM, Agboola SM, Adeoti AO. Prescribing Pattern and Utilization of Antihypertensive Drugs and Blood Pressure Control in Adult Patients with Systemic Hypertension in a Rural Tertiary Hospital in Nigeria. Am J Internal Med. 2014; 2(6):144-9.

10. Eraga SO, Odili VU, Iwuagwu MA, Igodo JO. Prescription Patterns of Antihypertensives and Drug Utilisation in a General Hospital in Minna, Niger State, Nigeria. Pak J Pharm. 2012; 25(1\&2):37-41.

11. Ukwe CV, Ubaka CM. Antihypertensive Drug Prescribing in a Tertiary Hospital in Eastern Nigeria. Trop J Pharm Res. 2012; 11(2):297-305.

12. Ekwunife OI, Ubaka CM. Drug Utilization Review of Antihypertensive Therapy among Patients with Compelling Indications in Two Hospitals in SouthEastern Nigeria. J Pharm Pharm Res. 2011; 2(1):25-8.

13. Olanrewaju TO, Aderibigbe A, Busar OA, Sanya EO. Antihypertensive Drug Utilization and Conformity to Guidelines in a sub-Saharan African Hypertensive Population. Int J Clin Pharmacol Ther. 2010; 48:68-75.

14. Etuk E, Isezuo SA, Chika A, Akuche J, Ali M. Prescription Pattern of Anti-hypertensive Drugs in a Tertiary Health Institution in Nigeria. Ann Afr Med. 2008; 7:128-32.

15. Federal Ministry of Health-Teaching Hospitals. Available from: http://www.health.gov.ng/index.php/parastatals/teachin g-hospitals. [Last updated on 2019 Oct, Last accessed on 30 $0^{\text {th }}$ July, 2018].

16. Yamane T. Statistics, An Introductory Analysis, $2^{\text {nd }}$ Ed. New York: Harper and Row. 1967.

17. WHO Collaborating Centre for Drug Statistics Methodology, Available from: http://www.whocc.no/ddd/list of ddds, 2015. [Last updated on 2018 Feb, Last accessed on $2^{\text {nd }}$ March, 2015].

18. Bergman U, Popa C, Tomson Y, Wettermark B, Einarson TR, Aberg $\mathrm{H}$, et al. Drug Utilization 90\% - A Simple Method for Assessing the Quality of Drug Prescribing. Eur J Clin Pharmacol. 1998; 54:113-8.

19. Federal Ministry of Health. 2005. National Health Insurance Scheme: Treatment Protocols and Guidelines. Abuja: Federal Ministry of Health: Nigeria.

20. Katibi IA, Olarinoye JK. Antihypertensive Therapy among Hypertensive Patients as Seen in the Middle Belt of Nigeria. Ann Afr Med. 2004; 3:172-80.

21. Ganiyu K, Suleiman IA. Assessment of Antihypertensives Utilization in a Private Teaching 
Hospital in Nigeria. Int J Pharm Pharm Sci. 2012; 4:480-3.

22. Adedapo ADA, Adedeji WA, Adeosun AM, Olaremi J, Okunlola CK. Antihypertensive Drug Use and Blood Pressure Control among in-patients with Hypertension in a Nigerian Tertiary Healthcare Centre. Int J Basic Clin Pharmacol. 2016; 5(3):696-701.

23. Tamuno I, Babashani M. Blood Pressure Control among Hypertensive Patients in a Tertiary Health Care Facility in Northern Nigeria. Res J Med Sci. 2012; 6:2632.

24. Awulor I. How Civil Servants Prepare for Retirement. Available https://thepointernewsonline.com/?p=5561. [Last updated on 2017 Jan, Last accessed on $30^{\text {th }}$ July, 2018].

25. Ganiyu KA, Erah PO, Suleiman Al. Medication Outcomes of Therapy in the Management of Hypertension and Diabetes Mellitus in Two Tertiary Health Institutions in Niger Delta Region. West Afr $\mathrm{J}$ Pharm. 2014; 25(1):68-77.

26. The ALLHAT Officers and Coordinators for the ALLHAT Collaborative Research Group. Major Outcomes in High-risk Hypertensive Patients Randomized to Angiotensin-Converting Enzyme Inhibitor or Calcium Channel Blocker vs. Diuretic: The Antihypertensive and Lipid-Lowering Treatment to Prevent Heart Attack Trial (ALLHAT). JAMA. 2002; 288:2981-97.

27. Clement YN, Ali S, Harripaulsingh S, Lacaille $\mathrm{K}$, Mohammed O, Mohammed S, et al. Drug Prescribing for Hypertension at Primary Healthcare Facilities in Trinidad. West Indian Med J. 2012; 61:43-8.
28. Jainaf Nachiya RAM, Parimalakrishinan $S$, Ramakrishnan Rao M. Study on the Drug Utilization Pattern of Antihypertensive Medications on OutPatients and In-Patients in a Tertiary Care Teaching Hospital: A Cross-Sectional Study. Afr J Pharm Pharm. 2015; 9:383-96.

29. Rovin CV, Padmaja U, Thomas P, Manju PMS. Prescription Pattern of Antihypertensive Drugs in a Tertiary Care Centre. Int J Recent Trends Sci Technol. 2015; 14:212-4.

30. Malhotra S, Pandhi P. Availability of Thiazide Diuretics in Chandigarh. J Assoc Physicians India. 2000; 48:943.

31. Donovan R, Bailey J. Angiotensin II Receptor Blockers (ARBs). Available from: https://www.healthline.com/health/heart-disease/arbs. [Last updated on 2018 Mar, Last accessed on $30^{\text {th }}$ July, 2018].

32. Yusuff KB, Balogun O. Physician's Prescribing of Antihypertensive Combinations in a Tertiary Care Setting in South Western Nigeria. J Pharm Pharm Sci. 2005; 8(2):235-42.

33. Chobanian AV, Bakris GL, Black HR, Cushman WC, Green LA, Izzo JL, et al. The Seventh Report of the Joint National Committee on Prevention, Detection, Evaluation, and Treatment of High Blood Pressure: The JNC 7 report. JAMA. 2003; 289:2560-72.

34. New Zealand Guidelines Group. New Zealand Cardiovascular Guidelines Handbook: A Summary Resource for Primary Care Practitioners. 2nd ed. Wellington: New Zealand Guidelines Group, 2009.

35. Nguyen Q, Dominguez J, Nguyen L, Gullapalli N. Hypertension Management: An Update. Am Health Drug Benefits. 2010; 3:47-56.

\footnotetext{
This is an Open Access article distributed under the terms of the Creative Commons Attribution License (http://creativecommons.org/licenses/by/4.0), which permits unrestricted use, distribution, and reproduction in any medium, provided the original work is properly cited.
} 